\title{
O ENCONTRO ENTRE CHUVOSOS E NEFELIBATAS: A NUVEM POLÍTICA
}

\author{
Caio Ricardo Bona Moreira ${ }^{1}$
}

\section{Resumo}

A partir da leitura do poema-fábula “Os Chuvosos”, de Wilson Bueno, proponho uma reflexão acerca da figura do nefelibata. No referido texto, o escritor narra a vida de seres que habitam o interior das nuvens. Esses personagens rabelaisianos formam uma família que se transforma, ao longo da narrativa, em gotas de chuva. As figuras do nefelibata e da nuvem podem ser lidas como sintoma da rarefação da matéria, ou seja, da desmaterialização da obra, tendendo para a dispersão, para o vapor. Ela é recorrente em artistas contemporâneos como Wilson Bueno, Tony Oursler e Oscar Bony, mas já aparece em poetas simbolistas do final do século XIX e início do XX que, por sinal, foram considerados, pejorativamente, como nefelibatas alienados. Intentamos extrair da leitura outra força que não aquela que viu na nuvem apenas alienação.

Palavras-chave: Wilson Bueno. Os Chuvosos. Nefelibata.

\section{Resumen}

De la lectura del poema-fábula de "Os Chuvosos", Wilson Bueno, propongo una reflexión acerca de la figura del nefelibata. En este texto, el escritor narra la vida de los seres que habitan en el interior de las nubes. Estos personajes rabelaisianos forman una familia que se convierte, en el transcurso de la narración, en gotas de lluvia. El nefelibata y la nube puede leerse como un síntoma de la rarefacción del sujeto, es decir, la desmaterialización de la obra, que tiende a la dispersión, al vapor. Se repite en artistas contemporáneos como Wilson Bueno, Tony Oursler y Oscar Bony, pero ya apareció en los poetas simbolistas de finales del siglo XIX y principios del XX que fueron considerados, peyorativamente, como nefelibatas alienados. La intención del artículo es extraer de la lectura una fuerza distinta de la que vió en la nube sólo alienación.

Palabras Clave: Wilson Bueno. Os Chuvosos. Nefelibata.

\section{Introdução}

\footnotetext{
Em verdade, é desconcertante para os homens o trabalho das nuvens. Elas não trabalham acima das cidades: Quando há nuvens não há cidades: as nuvens ignoram se deslizam por sobre nossa cabeça: nós é que sabemos que deslizamos sob elas: as nuvens cintilam, mas não é para o coração dos homens.

Ferreira Gullar, $O$ trabalho das nuvens
}

\footnotetext{
${ }^{1}$ Doutor em Teoria Literária pela (UFSC) Universidade Federal de Santa Catarina. Professor de Literatura Brasileira da FAFIUV (Faculdade Estadual de Filosofia, Ciências e Letras de União da Vitória), Campus UNESPAR. E-mail caiorbmoreira@hotmail.com
} 
O escritor brasileiro Wilson Bueno, no poema-fábula Os Chuvosos ${ }^{1}$, nos apresenta uma estranha comunidade de seres que moram nas nuvens. Essas figuras, que vivem em núcleos chamados famílias, estão sempre se procurando naquelas "nuvens bojudas e carregadas, nascidas para virarem chuva mal as rompa o elétrico serrote de um raio” (BUENO, 1999). Do encontro entre o pai chuvoso, gordote e calvo, com a mãe, dona chuvosa, nascem sempre quinze chuvinhas, nunca menos do que isso. Há casos de casais de chuvosos com até cinquenta filhotes-chuvinhas, confessa-nos o poeta. A fábula poderia ser lida como uma espécie de irmã mais nova da chuva Maria, protagonista do poema "Caso Pluvioso” (2009), de Carlos Drummond de Andrade. Maria é ao mesmo tempo, criatura e fenômeno. Impossível distingui-la da chuva, posto que a chuva era Maria e cada pingo de Maria ensopava o nosso domingo. Cláudio Daniel, ao escrever sobre Os Chuvosos, observa que o livro de Bueno, numa linguagem lúdica, de aparente singeleza e suavidade, parodia o estilo ficcional dos contos infantis, na linhagem dos Irmãos Grimm, Andersen e Perrault:

Ao criar personagens a partir de elementos inanimados da natureza, o autor utiliza o
recurso da prosopopeia [...]. Incluir Os Chuvosos no ciclo de bestiários de Wilson
Bueno pode parecer arbitrário, mas o autor permite essa aproximação, nas primeiras
linhas do relato, onde diz: "Estes animais, eu vos convido, era uma vez". [...] De
todos os relatos de Wilson Bueno, este é talvez o mais sutil, de ação mínima,
transparente, quase reduzida ao precipitar das águas sobre as lonjuras de nossa
sombria terra (DANIEL, 2004).

A essa comunidade de personagens, os Chuvosos, nascidos de um fenômeno meteorológico não explicado, poderíamos acrescentar os anjos alados, de Wim Wenders a Walter Benjamin, bem como os nefelibatas de Rabelais. Que sentidos eles nos trazem?

O crítico José Castelo, ao escrever sobre Os Chuvosos ${ }^{2}$, não hesitou em aproximar o poeta das personagens que compõe seu poema-fábula. Para ele, mais que a chuva, o personagem de Wilson Bueno é O Transitório: “esse senhor esfumaçado, sem rosto, figura brevíssima que transita de um lado para outro, surgindo abruptamente e desaparecendo quando menos se espera (um raio, um pé de vento, um trovão. Esse cavalheiro que vive nas nuvens” (BUENO, 1999). Ou seja, Wilson Bueno é um nefelibata. Não seria fortuito lembrar que a expressão era usada costumeiramente para caracterizar os poetas simbolistas do final do século XIX e início do século XX. Andrade Muricy, autor do importante Panorama do Movimento Simbolista Brasileiro, observou que um dos motivos de escândalo da poética simbolista se deu pelo seu "hermetismo", em que vimos entrar na poesia um "espírito de humor soluçante, e a frio” (MURICY, 1987, p. 49). Esse teria sido o motivo de seus poetas receberem o apelido pejorativo de nefelibatas, numa franca alusão aos personagens 
imaginados por Rabelais. Manuel Bandeira, em sua pequena antologia de poesia simbolista, lembrou que em Portugal alguém aplicou a Eugênio de Castro e seus seguidores o epíteto de nefelibata, e tanto lá como depois no Brasil “os simbolistas foram crismados com tal nome: eram sujeitos que falavam coisas estapafúrdias numa linguagem incompreensível: sujeitos que andavam nas nuvens” (BANDEIRA, 1967, p. 11). ${ }^{3}$

O crítico de arte Gonzaga Duque, em 1906, no texto "Imagistas Nefelibatas”, publicado na revista Kosmos, e posteriormente reunido no livro Graves e Frívolos (1910), comenta o termo nefelibata e a carga pejorativa que recebeu ao ser aproximado do universo simbolista:

Esquisito, estranho, inédito, este termo valia por uma troça, siflava e demolia. Era um cartucho de alvaiade. Verdadeiramente não ofendia, porque, por sua composição grega, queria dizer habitante das nuvens e na sua aplicação - pensamento inacessível ao comum dos homens, transcendentalismo. Mas, empregado sem o conhecimento do seu valor, é tão ridículo como uma carapuça de jornal velho. [...] Chamemo-la nefelibata (a estética simbolista), mas com um suave sorriso que não humilhe nem hostilize (GONZAGA DUQUE, 1910, p. 77-87).

O conceito, relacionado com a postura antimaterialista da poesia finissecular, que se caracterizou como um apostolado em nome do ideal, encontraria na figura da turris ebúrnea seu gesto não só de recusa de um mundo profano, fazendo referência assim à "fórmula com que os sacerdotes afastavam os não-iniciados no começo da cerimônia” (CAROLLO, 1996, p. 9), mas também à necessidade de materializar nessa postura uma posição diante da decadência percebida no mundo burguês, que resultou em uma recusa da realidade e do sujeito, tal como são compreendidos por correntes positivistas e cientificistas do período. Nasce aí não só a posição radical do poeta simbolista diante da linguagem que opera, tomando consciência dos mecanismos significantes que estão em jogo no seu trabalho, mas também a crítica radical que lhe é endereçada. Para dar apenas um exemplo, lembremos que a revista modernista Joaquim, editada em Curitiba por Dalton Trevisan, na década de 40, recusou o simbolismo, considerando-o como parte de uma literatura que não sintonizou a sua produção com os problemas do homem e do mundo. Não precisamos nos afastar muito para encontrar gestos semelhantes. Wilson Bueno, transformado no personagem Uílcon Blanco, por Miguel Sanches Neto, em seu roman a clef Chá das 5 com o vampiro, foi considerado também de forma pejorativa como uma espécie de nefelibata, destinado a criar meros rebuscamentos de linguagem. É o caso também da crítica de Wilson Martins que, ao analisar Pequeno Manual de Brinquedos, encontra em suas páginas "poemas de solfejos gratuitos a que falta a autenticidade existencial e humana” (MARTINS, 1996). 
Em vez de condenar o "nefelibata”, poderíamos tomar a "nuvem” como problema, vendo em seu gesto uma revolução, no entanto, não uma revolução rasteira que seria o resultado de uma concepção utilitarista da poesia; falamos de uma revolução em termos de linguagem. Se por um lado, o sentimento de missão, que foi uma constante na formação da literatura brasileira, perde em grande parte o seu sentido na poesia fin-de-sciècle, por outro não deixa de existir, pois passa a entrar numa zona de indeterminação, "na qual a sua ‘impolítica’, isto é, a tomada de posição de seu ‘fora’ e sua relação de ‘con’, é a sua posição política enquanto tal, é o que faz dela um corpo em relação a outros corpos, isto é, um corpo político (SCRAMIM, 2008, p. 12). Nesse sentido, a nuvem se revestiria também como um corpo político, sendo, assim, não um mero gesto de alienação, mas sintoma da rarefação da matéria. Vejamos outros nefelibatas.

\section{Céus e nuvens}

Em 1976, o argentino Oscar Bony, que desenvolveu várias experiências na tentativa de “desmaterializar” a obra de arte $^{4}$, pintou, de maneira bastante figurativa, céus repletos de nuvens brancas. A data é significativa, 1976, período do Golpe de Estado. Bony, que se interessou avidamente pela relação entre arte e política, bem como entre arte e violência, poderia ser questionado quanto ao fato de, em um momento conturbado como aquele do Golpe, optar por pintar céus e nuvens. No entanto, se analisarmos com mais cautela esse gesto, outras coisas cielos y nubes nos dizem.

Oscar Bony revitalizava com suas nuvens o gesto nefelibata. Se a opção pela turris ebúrnea nos simbolistas em geral é uma posição política, em Bony não é diferente, o que de certa forma redesenha as relações da poesia do século XIX com a arte que lhe é contemporânea. Bony sobrepõe com suas nuvens as do chuvoso Wilson Bueno e também as dos simbolistas, re-forçando não só os antigos nefelibatas, mas também a sua opção de trocar a terra pelo céu. Ou seja, age sobre esse passado, devolvendo a ele potência, e dele extraindo uma força capaz de “fermentar” a sua própria produção. É o que faz, por exemplo, com sua série de fotografias "baleadas", produzida na década de 90, em que atira com uma pistola em fotografias, interferindo em seus sentidos pré-determinados, e desmontando, assim, o caráter de reprodução da fotografia, já que o tiro, o “suplemento”, o “a mais”, instaura uma diferença, produzindo uma imagem que sinaliza para o choque de tempos. A nuvem de Bony poderia ser lida nesse contexto como o tiro que se imprime sobre a imagem do nefelibata, fazendo nascer do atrito das duas imagens a sua força dialética. 


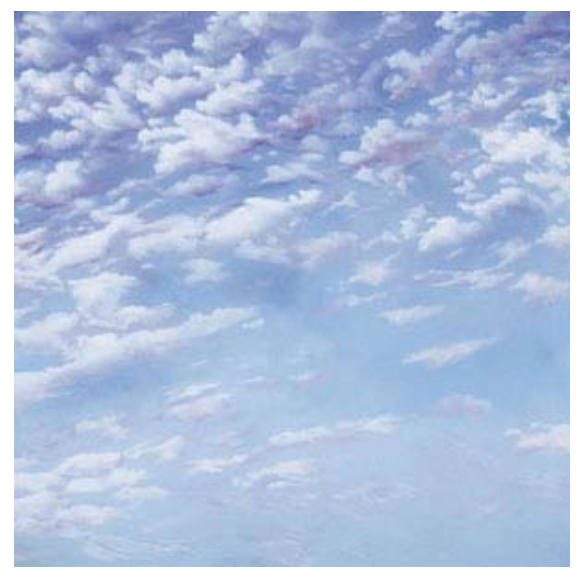

Figura 1 - Oscar Bony, Sin título, 1976.

Fonte: MALOSETTI, L, 2007

Em entrevista ao suplemento Cultura, do Diário Catarinense, Laura Malosetti observou sobre as nuvens do artista: "No ano do Golpe de Estado, em 1976, o Oscar Bony pintou céus, com nuvens brancas, perfeitamente naturalistas e figurativas, ou seja, tirou o olhar da terra e passou para o céu. Que é isto? Um ato político” (in PEDROSO, 2007, p. 3). Aliás, Malosetti inseriu um desses quadros na mostra Pampa, ciudad y suburbio, que organizou em Buenos Aires, em 2007, colocando-o numa rede anacrônica atravessada por outros artistas argentinos que se interessaram pela imagem da nuvem, como o pintor e arquiteto Prilidiano Pueyrredón, Antonio Berni e Roberto Aizenberg.

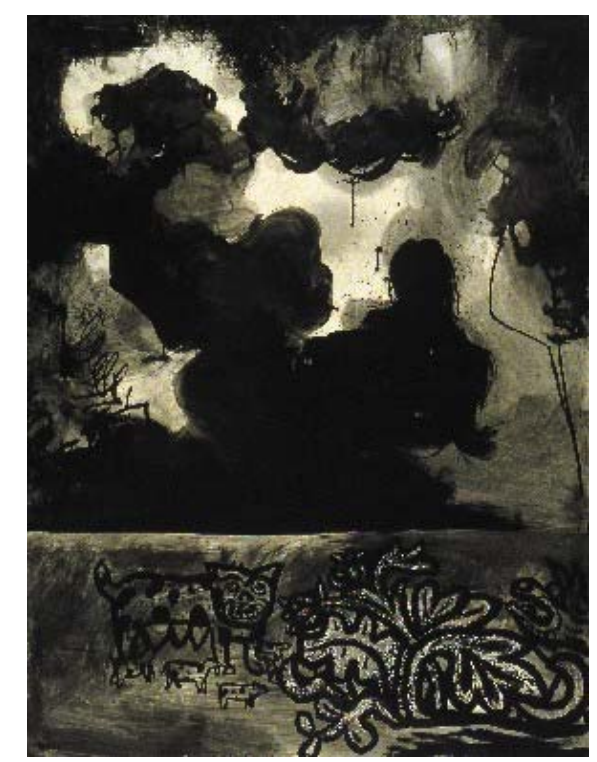

Figura 2 - Antonio Berni, Pampa y cielo, 1962. Fonte: MALOSETTI, L, 2007 
No caso de Pueyrredón, o que chama a atenção é a representação dos efeitos de luz gerados pelo céu pampeano. O céu em calmaria de Pueyrredón dará lugar, nos trabalhos de Antonio Berni e Roberto Aizenberg, a um céu obscuro, cuja presença ameaçadora se traduz em nuvens negras, que teriam por sua vez conotações fortemente políticas. No caso de Oscar Bony, mesmo não se tratando de nuvens negras, Malosetti não deixou de observar as suas intenções políticas, o que coloca em suspeita qualquer tentativa de interpretar o gesto nefelibata como destituído de preocupações terrenas:

Os céus pintados por Oscar Bony, em 1976, minuciosos e sutis estudos de nuvens brancas sobre um céu luminoso sem nenhuma referência ao plano terrestre, não podem deixar de pensar ao plano terrestre, pois são criados em um momento particularmente trágico, de golpe de Estado, repressão e desaparições (MALOSETTI, 2007, p.118).

Falávamos anteriormente na nuvem como sintoma da rarefação da matéria. Há um texto que pode nos ajudar a aprofundar o fato. Em 2002, T.J. Clark publicou na revista October o ensaio "Modernismo, Pós-modernismo e vapor”, em que discute a questão do "vapor” como sintoma da "nostalgia do infinito". Apesar de confessar não ser um especialista em arte contemporânea, - vivendo em um passado deliberadamente modernista - o ensaísta responde de maneira consistente a algumas questões relacionadas à arte do presente. Clark (2002) se refere à rarefação da matéria que permeia a arte contemporânea. O ensaio parte de uma imagem elaborada por Tony Oursler, presente na instalação intitulada The Influence Machine, de 2000.

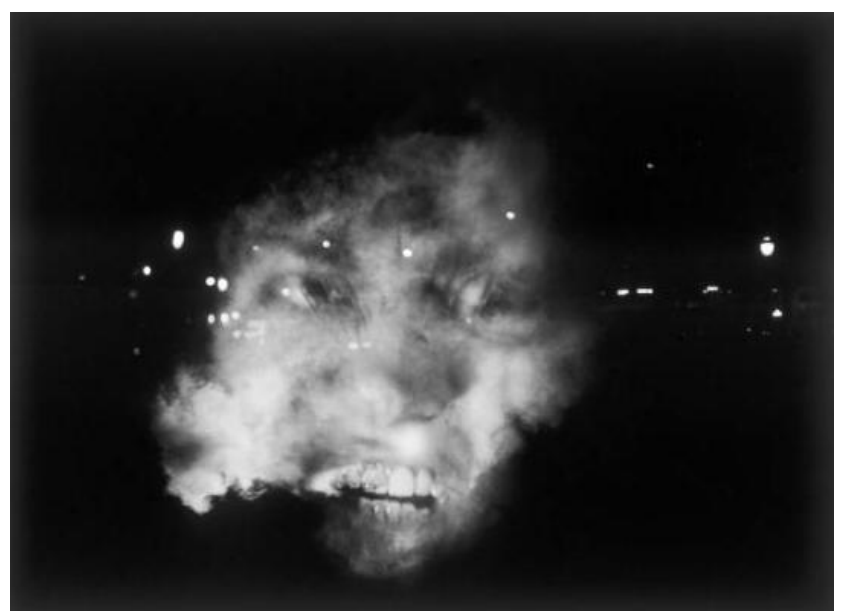

Figura 3 - The Influence Machine, 2000 Fonte: OURSLER, Tony, 2002

A foto mostra a imagem de um rosto projetado dentro de uma nuvem. Se por um lado o trabalho de Oursler pode ser relacionado com o mundo virtual da Internet, por outro suscita 
uma reflexão sobre a arte contemporânea em geral, sobre o seu desejo de se desmaterializar, sobre os seus exercícios de abstração, tendendo para a pura contingência, para a dispersão, para a poeira ${ }^{5}$. No entanto, o ensaísta percebe que a questão da nuvem já pode ser encontrada com força na arte do final do século XIX e início do século XX, o que o leva a problematizar o que se convencionou chamar de “pós-modernismo”. Tender para o “líquido” não é prioridade apenas do contemporâneo.

Clark confronta a imagem de Tony Oursler com alguns quadros modernistas, como Le Chemin de fer (década de 70 do séc. XIX), de Edouard Manet, e o Retrato de Maria Teresa, de Picasso, que, segundo ele, já faziam do vapor um sintoma não apenas de esvaziamento, mas também de poder, já que o vapor pode ser comprimido, tornando possível o mundo das máquinas.

Vale lembrar que no quadro A incerteza do poeta (1913), de Giorgio de Chirico, e em A Locomotiva, de Manet, são as locomotivas que produzem a fumaça, fazendo do vapor e da modernidade os dois lados de uma mesma moeda. Segundo o ensaísta, por um lado a máquina modernista prioriza o conhecimento técnico dos meios de trabalho, bem como o desenvolvimento de meios de ordenação, como se pode ver em Esportistas (1913), de Malevich, em que as barras pretas que separam os corpos em segmentos verticais dramatizam a dissolução da "imagem do mundo" em elementos formais, o que faz com que "modernismo" e "formalismo" estejam intimamente ligados. Por outro lado, surge o medonho e o fantasmagórico, já que a técnica não significa necessariamente a resolução de problemas. Assim, agonia e prazer, ordem e desordem, nesse momento, estão intimamente ligados. Manet, mesmo revelando na descontração de Le Chemin de fer algum tipo de perda ou horror, personificado no semblante desolado da governanta ao lado de uma menina (ambas parecem estar presas dentro de uma gaiola), não deixa de sugerir que ela continua sonhando, ou seja, nutrindo a nostalgia pelo infinito. O modernismo é, assim, entendido como uma de forma em agonia, mas uma agonia que não está separada do prazer. Ao ler o ensaio de T.J. Clark, precisamos ter em mente a condição dúplice que acompanha a questão: prazer e horror andam juntos. Se por um lado o modernismo louvou a máquina, o vapor, de outro, foi a oposição oficial da modernidade: Foi o pessimismo de uma modernidade eternamente otimista, uma resposta ao pragmatismo e à técnica da vida moderna, que, por sua vez, também seduziram aos modernistas.

Assim como T.J. Clark problematiza a oposição entre o modernismo e o pósmodernismo, pautado pela ideia de que seus fantasmas são os mesmos - e se não são os mesmos, pelo menos são bastante semelhantes -, poderíamos repensar a relação entre os 
modernistas e os nefelibatas, já que na poesia esses simbolistas bem poderiam figurar como os precursores de um problema que seria central na arte do século XX - e, em certo sentido, do século XXI também. Falo da rarefação da matéria como uma resposta ao pragmatismo e ao cientificismo da vida moderna. É o que vemos em Os Chuvosos, de Wilson Bueno, em que raios e trovoadas são descritos como o maior problema no interior das nuvens, onde vivem os chuvosos. Raios e trovoadas poderiam ser lidos aqui como alegorias do materialismo que sufoca os nefelibatas, materialismo capaz de apagar as velas, "fazendo-os perder os chuvinhas de vista” (BUENO, 1999, p. s/p) Mas lembremos que agonia e prazer não estão dissociados. Assim, o nefelibata, ao mesmo tempo, goza e sofre o mundo em que vive. Por sofrê-lo, imagina a nuvem como um habitat seguro e ideal, onde poderá gozar a realidade que criou. A realidade do texto e não a do mundo. Penso que essa poesia e esse poeta, situados em um mundo à parte, como a nuvem, compreenderam a estrutura de seu momento histórico, bem como previram a dispersão, a contingência, a pura vacância e a nostalgia do infinito que continuam marcando presença (a presença de uma ausência) na arte do presente, como nos mostra a imagem de Tony Oursler, ou mesmo as nuvens de Oscar Bony e de Bueno. Ao contrário dos "moços" da revista Joaquim, que viram nos simbolistas os medíocres e atrasados homens das nuvens, penso que esses nefelibatas foram os nossos primeiros poetas do futuro. Lembremos que, em janeiro de 1989, numa entrevista que talvez seja a última de Paulo Leminski, realizada por Denise Guimarães, para o Jornal Nicolau, o poeta discorreu sobre o simbolismo, e lembrou que o movimento soube perceber com mais profundidade as transformações sociais do final do século XIX do que o realismo socialista, o que bastaria para colocar em xeque a ideia da turris ebúrnea como mera evasão ou como gesto de covardia do artista nefelibata. Na revisão do simbolismo, em pleno fin-de-siècle, agora o $\mathrm{XX}$, o poeta encontrava na ilha de televisão uma espécie de torre-de-marfim:

Nicolau - Em várias oportunidades, você tem colocado uma espécie de tributo aos simbolistas. Neste fin-de-siècle como é que você se colocou sem uma "torre-demarfim”?

Leminski - Como sem “torre-de-marfim”? Uma ilha de televisão é uma “torre-demarfim”. O melhor lugar para você apreciar o mundo, descortinar com maior clareza o que se passa. Os simbolistas, de sua "torre-de-marfim”, viram o mundo social, a Revolução Industrial, o surgimento do proletariado com maior clareza. Eles fizeram uma leitura da sociedade industrial e seus conflitos, com muito mais profundidade do que aquele primatazinho realista-socialista, a la Jorge Amado, que pensa que fazer jornalismo é como fazer literatura (LEMINSKI, 1989, p. 8). 


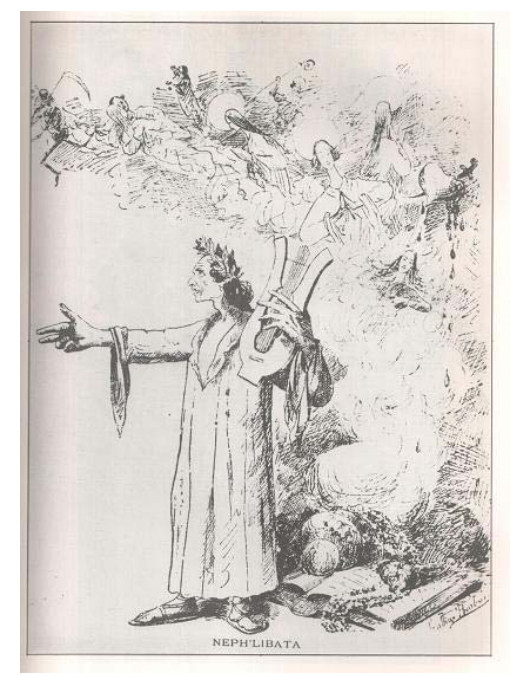

Figura 4 - Neph'libata, ilustração de Julião Machado, Fonte: CAROLLO, C. L, 1982

\section{Poesia sobre nada}

Para finalizar, gostaria de lembrar que é no mínimo curioso o fato de o poema-fábula de Wilson Bueno ter sido publicado em 1999, ou seja, em pleno fin-de-sciècle. Como não lembrar das hipóteses de Daniel Link, no texto "Utopias: dois umbrais”, em que o crítico celebra na figura de Rubén Dario o nosso fim de século. Os dois umbrais, do século XIX e do século XX, na iminência do XXI, sob seu ponto de vista, poderiam ser lidos como "dois momentos de perigo”, ou seja: “dois momentos utópicos da literatura” (2002, p. 138). E qual seria a utopia estética do fim de século? Link responde: “uma arte sem matéria”. Para Link, os poetas finisseculares, ao se jogarem com fervor na perseguição da arte pela arte para chegarem à “arte sobre nada”, puro estilo, conseguiram entender a lição de Flaubert, que em uma carta dirigida a Louisse Colet, em 16 de janeiro de 1852, confessa o seu desejo de escrever um livro sobre nada, que se sustentasse por si mesmo, pela força interna de seu estilo, como a "poeira se mantém no ar sem que a sustentem. [...] As obras mais belas são as que têm menos matéria [...] Acho que o futuro da arte está nessas vias” (LINK, 2002, p. 139). O hermetismo dos simbolistas, o arabesco, a riqueza ornamental, a busca pela nuvem, pelo puro estilo, e a obsessão pelo vazio seria, assim, o sintoma também de uma "poesia sobre nada”.

Se o futuro da arte está nessas vias, como sugeriu Flaubert, talvez a imagem de Oursler ou o poema-fábula Os Chuvosos, de Wilson Bueno, o confirmem. A arte sem matéria pode ser vaporosa como a nuvem. Cumpre ler com mais atenção as suas mensagens. Se por um lado seus gestos apontam para uma nostalgia do infinito, e nesse nefelibatismo encontram seu 
modelo político - chamando a atenção para outras formas de comunidade que não aquelas as quais estamos submetidos - por outro, fazem ressoar outra época, aquela que buscou a "arte sem matéria”, cujos ecos ainda repercutem. Não esqueçamos das palavras de Cláudio Daniel sobre o poema-fábula, poema-nuvem, poema-vapor: "De todos os relatos de Wilson Bueno, este é talvez o mais sutil, de ação mínima, transparente, quase reduzida ao precipitar das águas sobre as lonjuras de nossa sombria terra” (DANIEL, 2004).

Nuvens são passageiras, mas sempre voltam, com outros desenhos, outros contornos, em momentos de perigo, quando o tempo fecha. O nada, como Os Chuvosos nos ensinam, tem a sua própria política até que as nuvens se transformem em pingos de chuva e caiam sobre a terra, “múltiplos, gasosos, incessantes, transformados na névoa que deste lado se vê e que, feito um encanto, coroa os postes das madrugadas bêbadas de neblina” (BUENO, 1999). Resta saber se a sintaxe dessas nuvens e a lógica de seus encontros e caminhos continuarão produzindo uma chuva de encantos, ou serão dizimadas como os nefelibatas simbolistas, ou mesmo como Wilson Bueno, brutalmente assassinado no bairro Bacacheri, em Curitiba, na manhã de 31 de maio de 2010. Que este texto sobre a nuvem seja uma singela homenagem a ele.

\section{Referências}

ANDRADE, C. D. de. Nova reunião: 23 livros de poesia. V. 3. Rio de Janeiro: BestBolso, 2009.

ANTELO, R. Tempos de Babel: anacronismo e destruição. São Paulo: Lumme, 2007.

BANDEIRA, M. Antologia dos poetas brasileiros: poesia da fase simbolista. Rio de Janeiro: Edições de Ouro, 1967.

BUENO, W. Os Chuvosos. Curitiba: Tigre do Espelho, 1999.

CAROLLO, C. L. Do simbolismo aos antecedentes de 22. Curitiba : Secretaria de Cultura e Esportes do Paraná, 1982. p. 3

CLARK, T. J. Modernism, Postmodernism, and Steam. October Magazine, Massachusetts, n, 100, 2002.

DANIEL, C. Um zoo de signos: Os bestiários de Wilson Bueno. Zunái - Revista de Poesia \& Debates, out/ 2004). Disponível em: < http://www.revistazunai.com/ensaios/claudio_daniel_wilson_bueno.htm>. Aceso em 01 nov. 2011. 
. Uma conversa com Wilson Bueno. Disponível em:

<http://www.cronopios.com.br/site/artigos.asp?id=4594> Acesso em 01 nov. 2011.

GONZAGA DUQUE, L. Graves e Frívolos (Por assuntos de arte). Lisboa: Clássica, 1910.

LEÃO, R. de S. Entrevista com Wilson Bueno. 2002. Disponível em: <

http://www.gargantadaserpente.com/entrevista/wilsonbueno.shtml> Acesso em 01 nov. 2011.

LEMINSKI, P. Entrevista. Jornal Nicolau. Curitiba, n. 19, p.6-10, 1989.

LINK, D. Como se lê e outras intervenções críticas. Chapecó: Argos, 2002.

MALOSETTI, L. Pampa, ciudad y subúrbio. Buenos Aires: Fundación OSDE, 2007.

MARTINS, W. O culto delirante em torno de Leminski. 1996. Disponível em:

< http://www.jornaldepoesia.jor.br/wilsonmartins016.html> Acesso 29 novembro 2011.

MURICY, A. Panorama do movimento simbolista brasileiro. v. 1. São Paulo: Perspectiva, 1987.

OURSLE, Tony r. The Influence Machine. October Magazine, Massachusetts, 100, 2002. p. 154.

PEDROSO, N. Outsider da arte contemporânea (Entrevista com Laura Malosetti). Cultura Diário Catarinense. Florianópolis, p. 2-3, 29 dez 2007.

SCRAMIM, S. Modernismo, Simbolismo e Corpo In: Boletim de Pesquisa - NELIC Edição Especial Lindes. Florianópolis: Universidade Federal de Santa Catarina, 2008. Disponível em: <http://www.periodicos.ufsc.br/index.php/nelic/issue/view/994>. Acesso em: 20 julho 2011.

\footnotetext{
${ }^{1}$ O livro foi inicialmente publicado em 1999 pela editora Tigre do Espelho, em um bonito projeto gráfico de Jussara Salazar. Teve sua segunda edição pela Lumme Editor, que disponibilizou o conteúdo na Internet. Em edição bilíngue, Os Chuvosos foi publicado na Argentina pela Eloísa Cartonera, que promove a feitura de livros artesanais. O livro pode ser visualizado no seguinte endereço: $<$ http://www.cronopios.com.br/pocketbooks/oschuvosos/>.

${ }^{2}$ Não seria fortuito observar que apesar de Os Chuvosos ser considerado um livro de literatura infantil, não se reduz a uma peça circunscrita a esse gênero específico. É o que imaginamos neste trabalho ao devolver potência à imagem da nuvem e do nefelibata, refletindo sobre a força que essas imagens sustentam ao serem postas em rede. Bueno, em entrevista concedida a Rodrigo de Souza Leão (2011), ao ser perguntado sobre a diferença entre escrever para um público adulto ou infantil, observou que Os Chuvosos era seu único livro destinado para as crianças. Todavia, o livro não fora escrito com essa finalidade, apesar de ser dedicado a uma menina de cinco anos. Seu objetivo inicial era integrá-lo ao Jardim Zoológico, que não é propriamente um livro infantil. Em outra entrevista, realizada com Cláudio Daniel, ao ser interpelado sobre Os Chuvosos e perguntado se pretendia se dedicar mais à literatura infantil, Bueno responde: Não pensei direito nisto ainda... Eu diria que Os Chuvosos se destina, ao menos este é o meu desejo, a leitores dos 0 aos 100. E tem sido esta a recepção dos escassérrimos 50 exemplares "fabricados", um a um, à mão, como se fossem gravuras. Gente de todas as idades fica encantada com este livro. Mas ali tem o toque mágico da Jussara Salazar que reinventa o texto e faz dele no papel uma literal fulgurância (DANIEL, 2004).

${ }^{3} \mathrm{O}$ próprio Bandeira parece inserir uma carga pejorativa no termo, ao afirmar que o nefelibatismo não contaminou a obra de Cruz e Sousa, nem a sensibilidade de Alphonsus de Guimarães, ao contrário de Emiliano Perneta e Dario Vellozo. O que demonstra que entendia o nefelibatismo como prejuízo à poesia. Por
} 
isso confessou que se não atendesse ao seu gosto pessoal e não considerasse Vellozo e Perneta dois dos principais fundadores do simbolismo no Brasil, não os incluiria na antologia.

${ }^{4}$ Sobre esse interesse de Oscar Bony pela desmaterialização da obra de arte, vale lembrar da performance que o artista experimental, ligado ao Instituto Torcuato Di Tella, criou em 1968 e que foi intitulada La família obrera. Tratava-se de uma instalação em que um operário chamado Luis Ricardo Rodríguez juntamente com a esposa e um filho ficavam sentados sobre um bloco de madeira em um museu de Buenos Aires, simulando três estátuas. A conotação política era reforçada pela legenda que informava que Rodríguez recebera pelo serviço prestado na exposição o dobro do valor da sua hora de trabalho. Hoje, a performance é reproduzida em exposições por meio de fotografia, como aconteceu na $29^{a}$ Bienal de São Paulo, em 2010

${ }^{5}$ Sobre a questão da dispersão, da disseminação, da poeira, esmiuçada a partir de uma reflexão sobre a relação do artista com a destruição, com tempo e com a morte, Raúl Antelo dedica as páginas de Tempos de Babel: Anacronismo e destruição, texto que retoma a análise do crítico italiano Elio Grazioli sobre a questão da poeira na arte contemporânea. Pensando na poeira das Torres Gêmeas do 11 de Setembro, Grazioli vê na arte um momento de transformação: "Passando per l'arte, anche l'11 setembre 2001 alleva la propria polvere, si presenta come um nuovo inizio, Il bisogno di um ricominciamento” (apud ANTELO, 2007, p. 47). 